\title{
Oficina de GPS para pescadores na Reserva Extrativista do Batoque - Aquiraz /CE
}

\begin{abstract}
Resumo: Relato sobre uma experiência de ensinar realizada na Reserva Extrativista do Batoque - Ceará, com 14 pescadores, cuja grande maioria não sabia ler e escrever. Reflete sobre como pode-se dar a atuação do professor licenciado em Geografia diante de uma demanda comunitária, visando ensinar o instrumento de posicionamento global - GPS, através da relação entre sujeitos (professora e pescadores) situada em contextos diversos (conhecimento de GPS e nenhum conhecimento de pesca). A metodologia consistiu na realização de uma oficina de 20 horas com a utilização de desenhos e números em folhas de papel madeira, e, em seguida o manejo individual do aparelho de GPS por cada pescador, mas sem deixar de valorizar o saber dos pescadores em relação à pesca e deslocamento no mar. Os exercícios trabalhados proporcionaram ao grupo apreender o significado do uso da tecnologia na atividade pesqueira (marcar a localização/posição, inserir uma posição, direção dos ventos, distância em metros, quilômetros, rumo, grau, bússola e rotas). Constatou-se que a incorporação da tecnologia implica a possibilidade da mudança de uma tradição ("do segredo"). Houve troca entre o saber universitário e o saber cotidiano dos pescadores.
\end{abstract}

\section{GPS workshop for fishers in the Extractive Reserve Butts Aquiraz / CE}

\footnotetext{
Abstract: An account on a teaching experiment carried out on the Extractive Reserve of Batoque-Ceará, involving fourteen fishermen whose great majority was unable to read or write. This reflection focuses on how a Geography licensed teacher can act in face of a community need to learn how to use a GPS device. The methodology consisted in the setting up of a 20hour workshop using cardboard signs (drawings and numbers), followed by the individual handling of a GPS device, this way increasing the value of the fishermen's knowledge. The exercises drilled gave the group the opportunity to learn about the importance of using technology in its fish-catching activity (marking and entering a position, wind direction, distances in metres, quilometres, course, degrees, compass and route). It was observed that the incorporation of technology means a change in tradition, in the "secret of doing the thing." There was an exchange of ideas and information between university scholarship and the fishermen's everyday knowledge.
}

Alexsandra Bezerra Rocha*

*Doutoranda do Programa de PósGraduação em Geografia -UFC. Especialista em Desenvolvimento e Gestão do Território pela Universidade do Estado do Rio Grande do Norte - UERN.

Palavras- chave: Geografia Comunidade pesqueira; GPS; Troca de saberes.

Key-Words: Geography; Fishing community; Use of technology; Knowledge exchange. 


\section{Introdução}

1 Situa-se a $54 \mathrm{~km}$ de Fortaleza - CE. Limita-se ao Norte com 0 Oceano Atlântico, ao Sul com - município de Pindoretama, e ao oeste com a comunidade do Barro Preto, município de Aquiraz. 0 acesso é feito a partir da CE 040, rodovia estadual com pavimentação asfáltica até o município de Pindoretama. A partir daí é necessário percorrer $12 \mathrm{~km}$, por uma estrada vicinal sem pavimentação para chegar à comunidade.

2 O Sistema Nacional de Unidades de Conservação da Natureza - SNUC constitui-se em um conjunto das unidades de conservação federais, estaduais e municipais. Já a Reserva Extrativista é uma área utilizada por populações tradicionais, cuja sobrevivência baseia-se no extrativismo e, complementarmente, na agricultura de subsistência e na criação de animais de pequeno porte. 0 Decreto No 6.040, de 7 de fevereiro de 2007 instituiu a Política Nacional de Desenvolvimento Sustentável dos Povos e Comunidades Tradicionais - PNPCT.

3 A informação referente às coordenadas é segredo absoluto, só foi possível tirar a foto ilustrando os objetos de pesca e a folha com as coordenadas na casa de um dos pescadores, e mesmo assim ele não deixou abrir a folha, mas informou que escreve o nome do peixe e as coordenadas correspondentes.

Geografia Ensino \& Pesquisa, v. 16, n.2 p. 79 -88, maio/ago. 2012

Oficina de GPS para pescadores na Reserva Extrativista do Batoque Aquiraz /CE
O texto "Sobre nabos crus e professores" de Rubens Alves trata sobre o professor que não adota em sua prática docente a aprendizagem significativa dos seus alunos. Nesta direção, 0 que está em questão é como construir algo diferente com os alunos? Como despertar o interesse pela leitura, pelo diferente e pela reflexão? Como desenvolver diferentes tipos de metodologias e abordagens, capazes de alcançá-los? A partir destas questões focamos este texto na formação de uma licenciada em Geografia e na articulação e definição de tarefas coletivas (professor/aprendiz).

A formação do licenciado em Geografia está relacionada à teoria e a prática docente, vivenciada principalmente durante os estágios. A mediação simbólica, o papel do educador, a produção e a aplicação deste conhecimento, parte do princípio que teoria e exercício do magistério podem ser definidos e interpretados em função dos condicionantes e dos recursos que determinam a ação cotidiana, as ideologias, as crenças, os valores, interesses e a relação concreta entre professores e alunos. Segundo Tardif (2002, p. 176):

[...] o ensino é uma atividade humana, um trabalho interativo, é a socialização do conhecimento. É perseguir finalidades, elaborando estratégias e esquemas cognitivos e simbólicos, em função dos condicionantes (assunto, grau de dificuldade dos alunos, motivação, dentre outros).

Com base nestas questões, este trabalho tem por objetivo relatar a experiência durante uma oficina e a troca de saberes sobre o uso do Sistema de Posicionamento Global - GPS com pescadores do Batoque ${ }^{1}-\mathrm{CE}$, em que a maioria não sabem ler e escrever; em foco, as vivências destes trabalhadores com o mar e as possibilidades de uso do GPS durante as pescarias. A comunidade pesqueira marítima do Batoque é uma unidade de conservação de uso sustentável, denominada de Reserva Extrativista do Batoque ${ }^{2}$, e conta, atualmente, com aproximadamente 456 habitantes que vivem, principalmente, da pesca artesanal.

A pesca artesanal na comunidade do Batoque (Fig. 1) utiliza instrumentos como: (1) anzóis, (2) chumbadas, (3) cera em barbante para costurar a vela (4) linha náilon, (5) uma proteção de borracha no dedo indicador da mão direita e da mão esquerda (chamada de dedal pelos pescadores, entrelaçam a linha nas pernas e nos pés para não correr o risco de machucar o dedo), (6) cano de PVC para enrolar a linha náilon com os anzóis, de forma a levar tudo pronto para o mar, (7) barbantes para costurar as velas, e (8) alguns pescadores que já utilizavam o GPS escrevem as coordenadas em folhas de papel e guardam em um local "secreto"3.

Segundo Lima [...] a pesca artesanal tem grande relevância socioeconômica e cultural, principalmente, para aquelas comunidades que persisteme lutam por condições referenciais ao seu modo de vida, mas que há, também, um conjunto de atividades econômicas atuais que são realizadas de forma complementar, especialmente referenciada pelas práticas do extrativismo, de pequenos plantios, do artesanato local, pelo comércio e oferta de serviços - mais recentemente, pela prestação de serviços domésticos e vinculados ao turismo (hospedagem, alimentação e entretenimento) (2002, p. 95). 


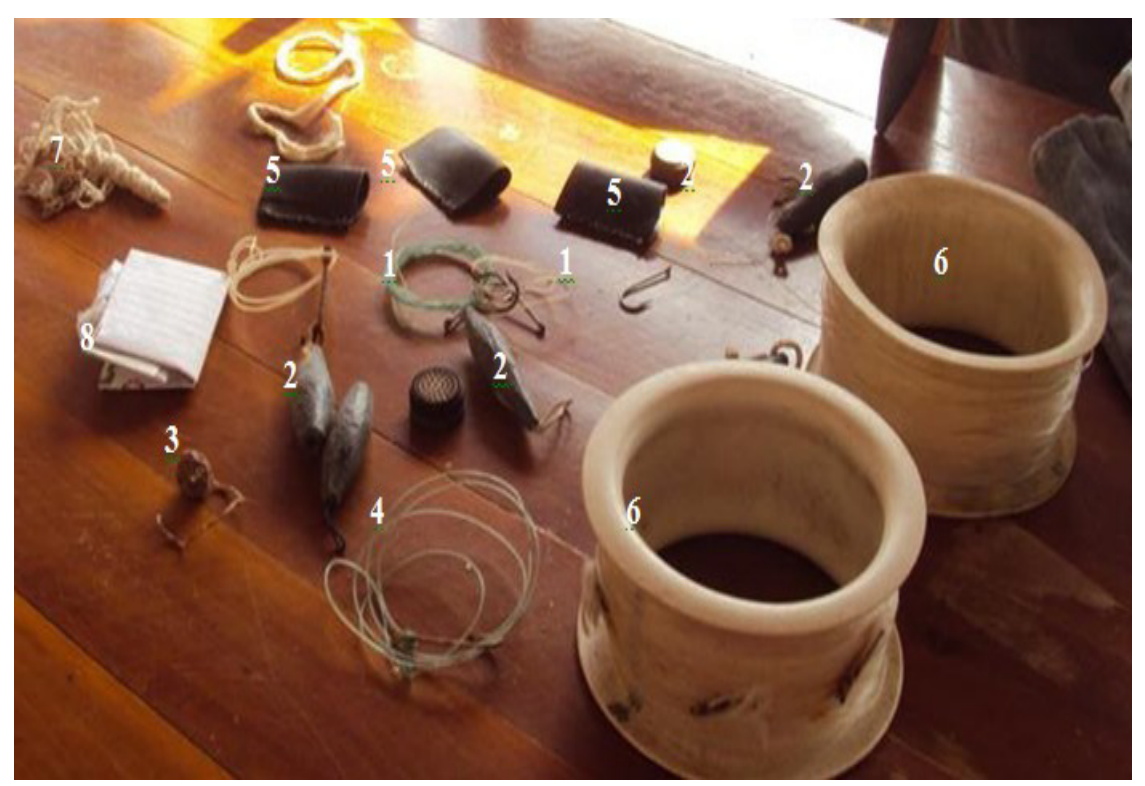

Figura 1- Instrumentos utilizados na pesca artesanal. Fonte: Rocha, 2011.

\section{O GPS e as implicações tecnológicas em diferenciados contextos}

O uso do sistema de posicionamento global por satélite está cada vez mais presente na vida cotidiana, vendido em diversos formatos e modelos, e também para fins específicos.

Segundo Monico (2000) o primeiro sistema de satélites colocado à disposição do público civil foi o TRANSIT (1967). Em 1973, o NAVSTAR/GPS veio para alcançar melhores precisões. O sistema de posicionamento global (GPS) foi criado em 1978 pelo Departamento de Defesa dos Estados Unidos, e era utilizado somente por militares, em 1983 esse sistema foi colocado à disposição do público em geral com algumas restrições.

Desta forma era possível obter a precisão de posicionamento durante a navegação igual ou inferior a 100 metros. Em maio de 2000, o Departamento de Defesa Americano retirou essa restrição e atualmente durante a navegação com um receptor é possível obter precisão de localização de aproximadamente 7 metros.

As principais vantagens na utilização do GPS são: 0 uso em transportes e deslocamentos aéreos, marítimos ou terrestres, traçar rotas, conhecer distâncias reais percorridas, estabelecer trajetos, marcar determinado local (posição) e retornar a qualquer momento. Serve também para mapeamento de redes elétricas, limites de propriedades rurais, cadastro e manutenção de obras na construção civil. Os dados coletados com o GPS são armazenados, gerenciados, analisados e tratados, e, posteriormente, a automatização desta tarefa facilita a realização de análises complexas, através da possibilidade de integração dos dados obtidos.

No ambiente universitário, o GPS é uma ferramenta utilizada por diversos campos disciplinares (Geografia, Geologia, Agronomia, Biologia, Ciências Ambientais, Medicina, entre outros). No geral, a incorporação desta técnica, significa maior precisão nos mapeamentos, localização de pontos específicos (tipo de rocha, voçorocas, afloramentos, fauna, flora, recursos ambientais, comércios, indústrias, lagoas, degradação, poluição, incidências de doenças em diferentes bairros, dentre outros).

Seguindo as recomendações de Pimenta (2010), seria necessário introduzir estudos em áreas específicas, buscando superar as demandas que surjam no processo de ensino-aprendizagem. Só assim tornará possivel a construção do fazer didático contextualizado.

O trabalho realizado por Bezerra e Scartazzini (2006) utilizando GPS como fator de motivação e recurso didático no ensino fundamental apresenta uma proposta alternativa de ensino-

Geografia Ensino \& Pesquisa, v. 16, n.2 p. 79- 88 , maio/ago. 2012

Rocha, A. B. 
aprendizagem da geometria analítica. Os autores exploram temas como: escalas, coordenadas cartesianas no plano, equação da reta, teorema angular, distância de ponto a reta e determinação de áreas das figuras planas irregulares.

No universo das comunidades tradicionais, a incorporação tecnológica é a mudança de uma tradição. Saber usar o GPS e ter os registros dos pontos permite a localização (posição) dos melhores pontos de pesca. A informação não é dividida com outros, é guardada, é segredo absoluto $^{4}$. É parte do poder antes controlado pelos mestres, agora à disposição dos que detém a posse do instrumento de trabalho.

De acordo com Lima (2002), na pesca artesanal há regras para a composição dos grupos de trabalho, definidos segundo critérios de competência, lealdade e parentesco. Os integrantes são coordenados pelo mestre pescador, responsável pela divisão de tarefas, pela estruturação do poder e pela conformação das relações no interior da embarcação.

\section{Experiências e saberes com uso do GPS no processo de ensino-aprendizagem}

As principais circunstâncias que conduziram o desenvolvimento da oficina de GPS na Reserva Extrativa do Batoque foram motivadas pela troca de experiências e vivências do saber acadêmico com o saber-fazer dos pescadores apreendidos com as práticas cotidianas sobre diferenças entre ângulos, retas, quilômetros, milhas, direção dos ventos e principalmente o grande interesse e motivação para aprender a manejar um novo equipamento que já faz parte da rotina de alguns pescadores na comunidade e de outras localidades.

A metodologia utilizada consistiu na realização de uma oficina de 20 horas sobre 0 uso de GPS para 14 pescadores, todos com aparelhos para uso individual. Tendo em vista que a grande maioria não sabia ler e escrever, não tinha sentido usar, por exemplo, uma exposição em power point, trabalhamos com cartazes em papel madeira (com desenhos e números). Apenas três destes alunos já conheciam e utilizavam o GPS nas pescarias. Estes foram escolhidos para auxiliar durante

${ }^{4} \mathrm{~A}$ noção de segredo é essencial para a compreensão da realidade pesqueira. Essa noção corrobora no entendimento do processo de apropriação dos recursos naturais; no desvendar das relações de poder, de prestígio e de autoridade. Em síntese, "a atitude de segredo é recorrente sempre que se convive com pescadores, tanto no âmbito tradicional como no industrial como um elemento ético inalienável à atividade pesqueira" (MALDONADO, 1993 apud, LIMA, 2002, p. 30).

Geografia Ensino \& Pesquisa, v. 16, n.2 p. $79-88$, maio/ago. 2012

Oficina de GPS para pescadores na Reserva Extrativista do Batoque Aquiraz /CE

82

ISSN 2236-4994 toda a oficina. Como estratégia de mediação recorreu-se aos exemplos cotidianos e as próprias vivências dos pescadores, em terra e no mar.

A linguagem e as formas metodológicas durante a oficina, aqui colocadas como ensinoaprendizagem, procurou observar o perfil dos alunos (20 a 63 anos), em sua maioria analfabetos, sem renda fixa, e em grande parte sem nenhuma experiência com aparelhos de GPS, mas como uma enorme capacidade de absorção e assimilação do conhecimento.

0 conhecimento adquirido durante a formação e o complementar compartilhado com os pescadores buscou atingir os objetivos e as finalidades do grupo, tentando suprir as dificuldades e os desafios da própria formação, buscando aprimorar a prática docente pedagógica, observando as possibilidades para constituição das teorias, das intuições, do bom-senso e a troca de saberes. Vários argumentos serviram de base para a defesa deste ponto de vista: Alvarez Méndez (1990), Laneve (1993), Moreira (2001), Nóvoa (2002), Tardif (2002, 2010), Abreu et al (2006), Cavalcanti (2006), Passos (2009), Pimenta (2010).

No início da formação tivemos momentos de trocas visando adequar à linguagem científica ao saber popular. Observou-se que marcação de pontos, ou obtenção de coordenadas, eram conhecidos por eles como marcação da posição dos locais de pesca; o que chamamos de rumo eles conheciam só como graus. Observando as ideias de Tardif (2002) percebe-se que: 
Apesar do planejamento realizado, durante a oficina de GPS foi necessário adaptar algumas estratégias e esquemas cognitivos simbólicos em função dos condicionantes estabelecidos pelo grupo de pescadores: a) grau de dificuldade do assunto: b) processo de assimilação do conhecimento (capacidade cognitiva, motivação, compreensão da importância da utilização do aparelho de GPS para pesca artesanal), c) local de realização da atividade (uma barraca de praia) (Fig. 2). Foi fundamental trabalhar questões específicas para a pesca: aprender a marcar a localização/posição, inserir uma posição no GPS, direção dos ventos, distância em metros, quilômetros, rumo, grau, bússola e criação de rotas.

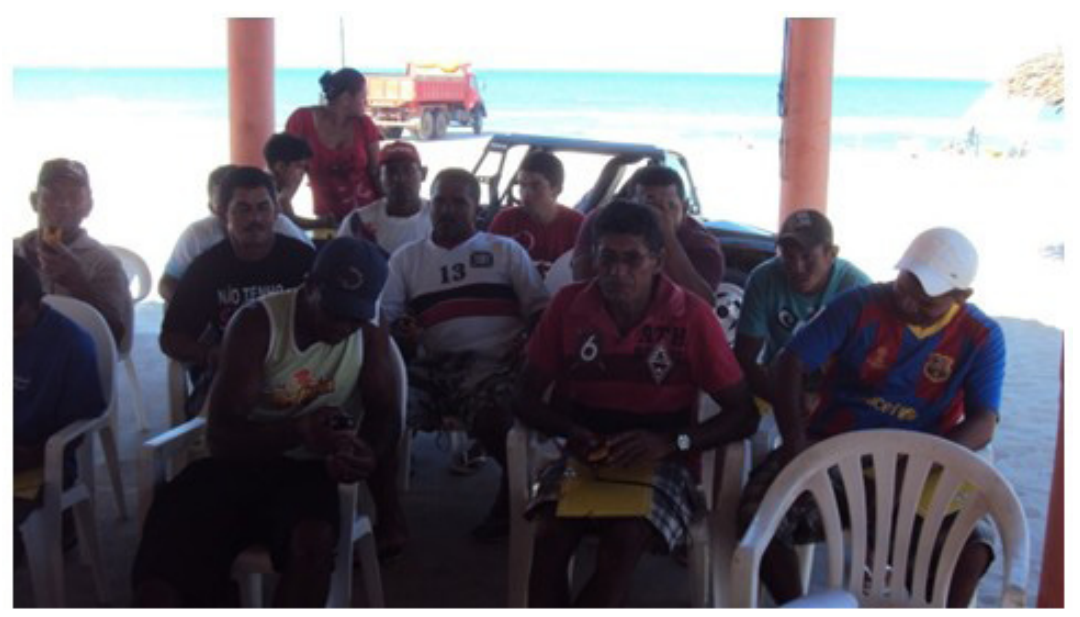

Figura 2- Oficina de GPS para pescadores da comunidade do Batoque - CE. Fonte: Rocha, 2011.

De acordo com Gauthier (1998, p. 27) os saberes da docência, estão relacionados com a mobilização dos professores frente às questões que surge no processo ensino-aprendizagem [...] É "a mobilização de vários saberes que formam uma espécie de reservatório no qual o professor se abastece para responder as exigências específicas de sua situação concreta de ensino" (p. 27).

$E$, além disso, é necessário entrar de corpo e alma na docência, extraindo dos professores o que há de melhor, ou seja, ensinar exige: rigorosidade metódica, pesquisa, respeito aos saberes dos educandos, criticidade, estética e ética, risco, consciência do inacabamento (FREIRE, 1998).

Daí a necessidade de fazer escolhas constantemente em plena interação com os pescadores. Para os que não sabiam ler inicialmente foi ensinado a manusear o aparelho de GPS, partindo da colocação das pilhas, da observação da quantidade de botões e funções respectivas, houve também a necessidade de passar alguns códigos (lado direito botão das páginas e 0 de ligar/ desligar, do lado esquerdo existem três botões o de zoom mais e zoom menos e o botão de Enter, este será o mais utilizado).

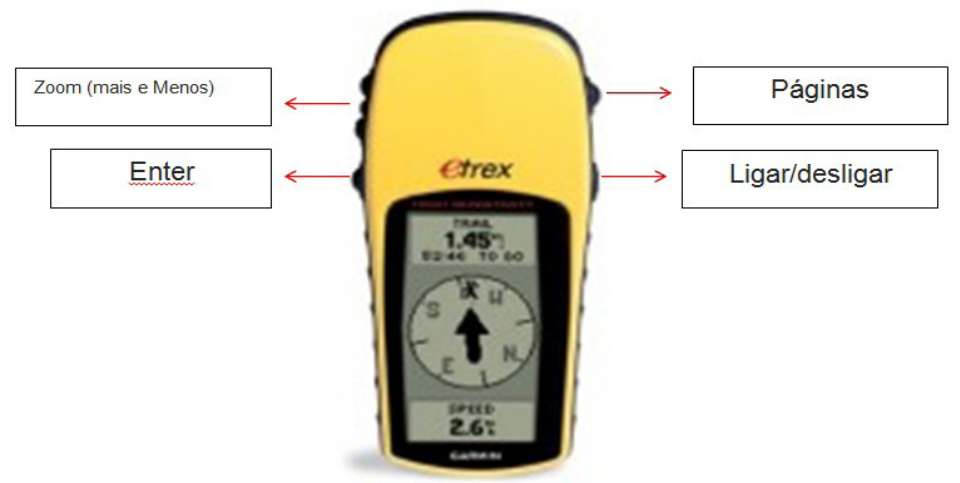

Geografia Ensino \& Pesquisa, v. 16, n.2 p. 79- 88, maio/ago. 2012

Figura 3- Modelo de GPS utilizado durante a oficina, este GPS Garmin tem todos os menus em português, arquivos detrilhas automáticas, é possível salvar até 10 trilhas, computador de viagem, tela LCD, corpo a prova d'água, autonomia de 22 horas com duas pilhas alcalinas.

Rocha, A. B. 
5 O GPS foi configurado na projeção UTM, Datum SAD 69 , coordenadas geográficas e sistema métrico (Os pescadores do Batoque baseiam os deslocamentos no mar em metro e em quilômetro).
Partindo deste acordo iniciamos a configuração do GPS e a indicação de algumas questões teóricas importantes: (1) a principal utilidade do aparelho GPS é indicar a sua localização no espaço; (2) a qualquer hora do dia ou da noite que você ligar seu GPS terá pelo menos 3 satélites disponíveis; (3) só poderá marcar uma posição quando tiver pelo menos quatro satélite a sua disposição, isto porque, terá a informação não só da latitude, longitude mas também da altitude; (4) nunca poderá marcar uma posição entre 12:00 horas e 14:00 hora, porque nestes horários, a radiação solar é muito forte no Nordeste, causando interferência na leitura e rastreio dos satélites ocasionando uma informação errada, ou seja, as coordenadas podem ficar a dezenas de metros de distância do local de marcação; (5) indicamos alguns símbolos para que o pescador possam salvar as posições no GPS, as distâncias, o tipo de peixe e as toneladas encontradas em uma caderneta ou folha de papel; (6) Os dois primeiros números das posições (Coordenada Geográfica) nunca irão mudar no Batoque $\left(03^{\circ}\right.$ e $\left.38^{\circ}\right)$, o que muda são os minutos e segundos, portanto, a partir do momento que estes dois números mudarem, significa que está em outro território e que precisa voltar; (7) a ferramenta pode ser utilizada por qualquer pessoa, independente de saber ler ou formação, é simples e fácil; (8) Só precisará configurar uma única vez (escolher projeção, datum, língua, hora/dia, sistema métrico); (9) Para marcar uma posição é só apertar enter e se necessário escolher um número ou nome (Fig. 4) para este ponto; (10) para conseguir encontrar os pontos de pesca é necessário observar e entender a linguagem da bússola;

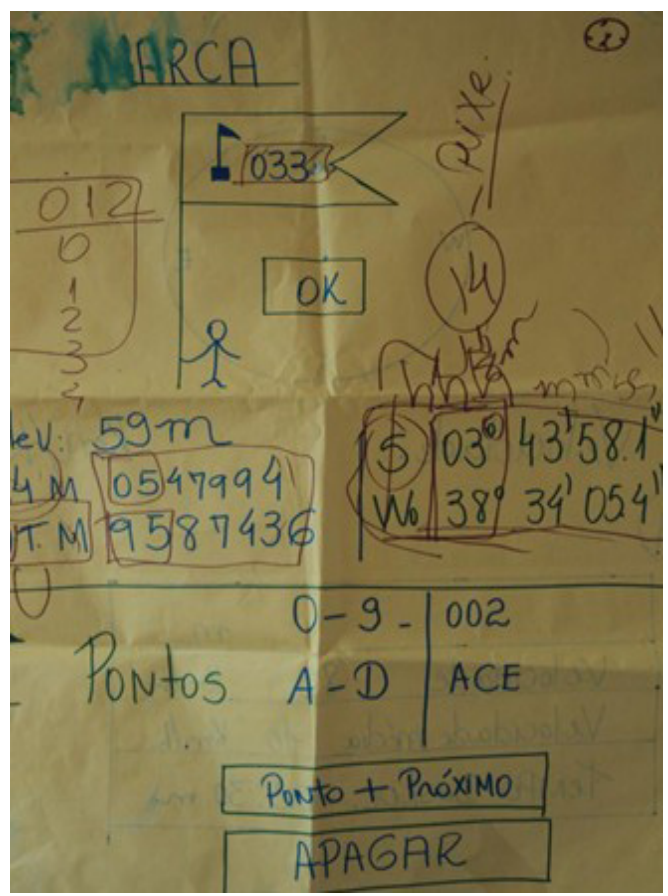

Figura 4- ensinando a modificar o número da posição e mostrando que os primeiros números das coordenadas nunca mudam.

(11) Existe um item chamado caça e pesca (Fig. 5), que faz um prognóstico do melhor horário para pescar e para voltar da pescaria. (12) Marcar pelo menos quatro pontos comuns antes de ir para o mar, para evitar que a embarcação encalhe, ou que a embarcação vá pra outra região. 


Caça e Pesca
18 de novembro de 2011
Melhor horário
02:10 - 04:30
$06: 00-08: 00$
$15: 00-16: 00$
$18: 00-20: 00$

Figura 5- Mostrando as vantagens do item caça e pesca.

Com o avançar da atividade foi perguntado qual era a maior dificuldade do grupo de pescadores até aquele momento. As respostas indicaram que a maior dificuldade para a maioria dos participantes foi entender a bússola, saber marcar e encontrar os pontos de pesca no mar. Para resolver a questão foi feito o desenho da bússola (Fig. 6) e explicou-se que existem alguns itens chaves, a serem considerados:

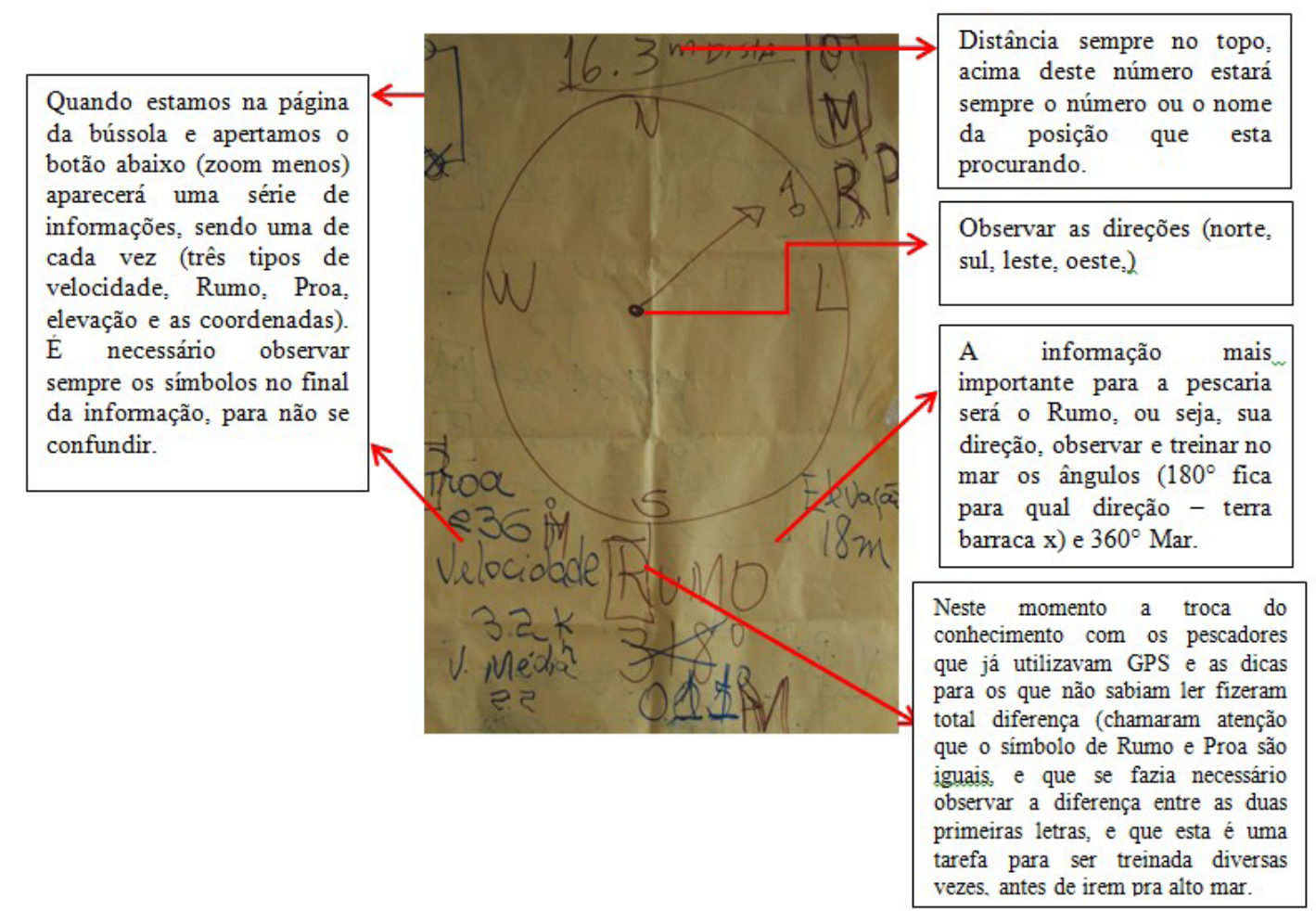

Figura 6 - Página da bússola

Então, diante de todas as sugestões e dúvidas dos pescadores, pedimos a alguns dos participantes para irem até um determinado ponto da praia, marcar uma posição, e solicitamos ao grupo inserir estas coordenadas nos GPS e depois procurar, pela bússola, sua localização (Fig. 7). 0 exercício foi refeito diversas vezes até todos pescadores estarem cientes e seguros de que tinham aprendido a realizar a atividade. É importante ressaltar que o GPS informa que o usuário localizou a posição que estava procurando 


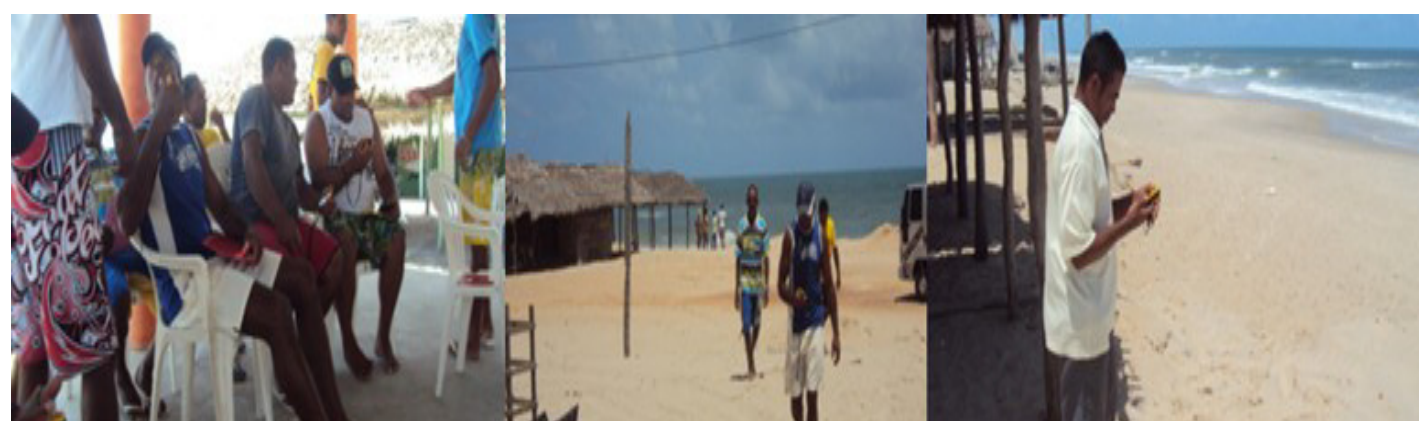

Figura 7- Inserindo as coordenadas no GPS e logo em seguida procurando a direção pela bússola, observando o rumo, à distância e as estratégias. Fonte: Rocha (2011).

As direções no mar são diferentes das direções em terra. Com experiência de quem se desloca no mar um dos pescadores representou o que é chamado por eles de processo de triangulação (Fig. 8), para que pudéssemos realizar a tarefa da forma mais real possível.

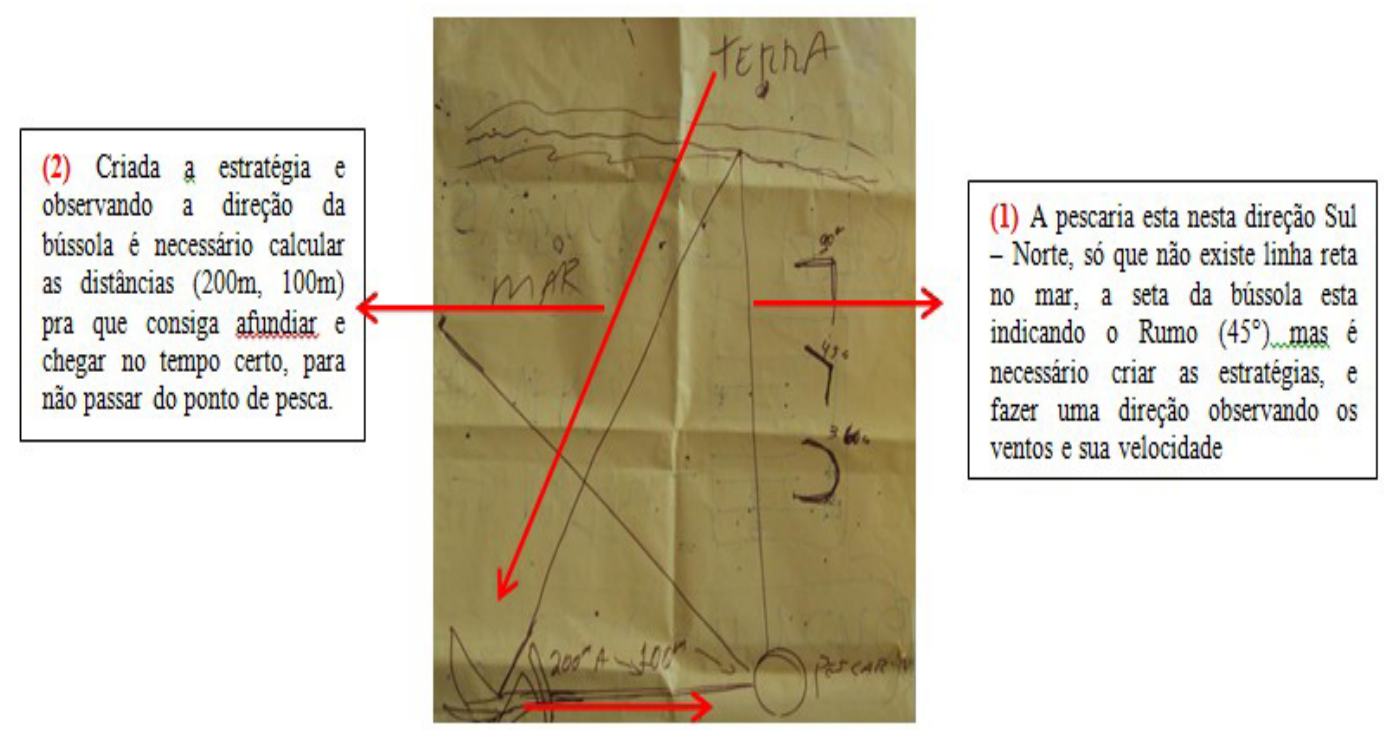

Figura 8- Direção da pescaria e possíveis estratégias para os pescadores.

Estes momentos de trocas de saberes corroboram com o pensamento de Pimenta (2010) quando afirma que ensinar é a relação entre sujeitos (professora e alunos) situados em contextos diversos (conhecimento de GPS e nenhum conhecimento de pesca), perpassando pelas questões culturais, espaciais, temporais e sociais. A junção dos saberes sanou limitações de ambos no processo ensino-aprendizagem. Transformando os sujeitos envolvidos neste processo, resignificando a prática docente e a experiência dos pescadores.

O conhecimento do professor (a) tem dimensão teórica, prática e experimental. A ação

Geografia Ensino \& Pesquisa, v. 16, n.2 p. $79-88$, maio/ago. 2012

Oficina de GPS para pescadores na Reserva Extrativista do Batoque Aquiraz /CE educativa esta sempre se reconstruindo seja através da prática, do aperfeiçoamento pessoal e profissional (NÓVOA, 2002). Ou seja, os saberes da experiência, vivências são tomados como ponto de partida e, intermediados pela teoria, se voltam para a prática. (PIMENTA, 2010).

A formação do professor é sempre contínua, exige estímulo, responsabilidade e conscientização do seu papel social. 


\section{Conclusões}

A proposta apresentada para desenvolver esta oficina com os 14 pescadores da Comunidade do Batoque visou despertar a motivação do grupo, superar os desafios eas dificuldades (conhecimento de GPS, nenhum conhecimento de pesca por parte da educanda e a maioria dos alunos não sabiam ler e escrever), inicialmente, entendíamos ambas as limitações, e fazia necessário trazer a teoria, sistematizando os tópicos, de forma que todo o grupo entendesse e compreendesse a necessidade e importância da aplicação do uso do GPS na pescaria. A intelococulação com Freire (1996) ajudou a intermediar o processo de ensino-aprendizagem. Ele nos ensina que [...] "o bom professor é o que consegue, enquanto fala trazer 0 aluno até a intimidade do movimento de seu pensamento. Seus alunos cansam, não dormem. Cansam porque acompanham as idas e vindas de seu pensamento, supreendem suas pausas, suas dúvidas, suas incertezas" (1996, p.96). Estas questões foram percebidas em alguns momentos da oficina, principalmente no período da tarde, que nesta parte do Nordeste a temperatura chega a $29^{\circ}$ no mês de novembro, período da realização da atividade.

As atividades práticas realizadas tiveram como foco: a bússola, grau, direção e deslocamento no mar para encontrar os pontos de pesca, dentre outras questões. Mas foi necessário fazer uma serie de adaptações para a tramissão do conhecimento. A troca de saberes com os pescadores foi fundamental para a realização da atividade. A experiência serviu para conciliar teoria e a prática profissional do pescador. Essencial foi à articulação e a definição das tarefas através de um processo coletivo (professor/aprendiz) para as opções necessárias à aprendizagem significativa.

Os campos no processo de ensino-aprendizagem são amplos, exigindo sempre o repassar sobre a prática, especializações e possibilidades criativas e uma busca contínua da formação e da aprendizagem. A elaboração e execução desta oficina foi sem dúvida um enorme desafio. Relatar esta experiência constitui no elaborar sobre como se deu a prática docente. Uma vez que foi necessário considerar as reais necessidades dos pescadores, o saber popular, conciliando teoriaprática, deu-se as escolhas, a articulação e a definição das tarefas através de um processo coletivo (participantes/professora).

Saber que hoje o uso do GPS na comunidade do Batoque faz parte dos instrumentos de trabalho da maioria e que tem gerado retorno ao grupo de pescadores é bastante significante. As coordenadas não estão sendo reveladas, nem a quantidade exata do pescado, diferentes de outras regiões é bem difícil alguém espacializar através de um mapeamento a localização dos pontos de pesca desta comunidade.

\section{Agradecimentos}

A profa. Dra. Maria do Céu de Lima do Departamento de Geografia da Universidade Federal do Ceará-UFC, por apresentar com toda singeleza e significado a história, cultura e a vida sobre os Povos das Comunidades Pesqueiras do Estado do Ceará e pela revisão e melhor estruturação deste artigo. Ao convite e confiança para ministração da oficina de GPS feito pela Msc. Cicera Inara Oliveira Sousa Borges articuladora comunitária da Rede de Turismo Comunitário do Ceará - Rede Tucum.

\section{Referências}

ABREU, P. R. F de; CARNEIRO, A. F. T. A Educação cartográfica na formação do professor de geografia em Pernambuco. Revista Brasileira de Cartografia. № 58/01, Abril de 2006.

BEZERRA, N.J.F; SCARTAZZINI, L.S. O uso do GPS como fator de motivação na aprendizagem da geometria analítica. Revista Acta Scientiae. Canoas. N²/8, Jul./dez de 2006.

Geografia Ensino \& Pesquisa, v. 16, n.2 p. 79- 88, maio/ago. 2012

Rocha, A. B. 
FREIRE, Paulo. Pedagogia da Autonomia: saberes necessários à prática educativa. 7a edição. São Paulo: Paz e Terra, 1996.

GAUTHIER, Clermont (et. al). Por uma teoria da pedagogia: pesquisas contemporâneas sobre o saber docente. Tradução Francisco Pereira - Coleção Fronteiras da Educação. ljui: Ed. UNIJUÍ, 1998.

LANEVE, C. Por uma teoria didática, Brescia, La Scuola, 1993.

LIMA, M. do C. Comunidades pesqueiras marítimas no Ceará: território, costumes e conflitos/. - Tese (Doutorado), Universidade de São Paulo - USP - FFLCH, São Paulo, 2002. 220f.

MALDONADO, S. C. Mestres \& mares: espaço e indivisão na pesca marítima. São Paulo: ANNALUME, 1993.

MONICO, J. F. G. Posicionamento pelo NAVSTAR-GPS: Descrição, fundamentos e aplicações. São Paulo: UNESP, 2000.287p.

MOREIRA, A. F. B. Currículo, cultura e formação de professores. Educar, Curitiba, N 17, p 3952, editora UFPR, 2001.

NÓVOA, A. Concepções e práticas de formação continua de professores. In: NÓVOA, A. Formação de professor e trabalho pedagógico. Lisboa. Educa, 2002.

PASSOS, C. M. B. Contemporaneidade e ressignificação da identidade docente no ensino superior. XII ENDIPE - Encontro Nacional de Didática e Prática de Ensino, 2004. Anais... Curitiba-PR. p. 843-855.

PIMENTA, S. G. Epistemologia da prática resinificando a didática. In: FRANCO, M. A. S; PIMENTA, S. G (ORG) Didática embates contemporâneos. Ed Loyola, 2010, São Paulo.

PIMENTA, S. G; ANASTASIOU, L. das G. C. Docência no Ensino Superior. $4^{a}$ edição. Cortez, 2010.

TARDIF, M. Saberes docentes e formação profissional. Petrópolis, Rio de Janeiro, vozes. 2002.

\section{Correspondência:}

Alexsandra Bezerra Rocha - Universidade do Estado do Rio Grande do Norte. Av rio branco 707, central. Cep. 59611-400 - Mossoro, RN - Brasil

E-mail: alexsandrarocha2@hotmail.com

Recebido em 25 de dezembro de 2011.

Geografia Ensino \& Pesquisa, v. 16, n.2 p. 79 -88, maio/ago. 2012

Revisado pelo autor em 13 de julho de 2012.

Oficina de GPS para pescadores na Aceito para publicação em 03 de setembro de 2012.

Reserva Extrativista do Batoque Aquiraz /CE 